\title{
KINERJA KARYAWAN DITINJAU DARI MOTIVASI, PROFESIONALISME DAN KOMITMEN ( STUDI KASUS PADA BAGIAN UMUM PEMDA SUKOHARJO )
}

\author{
Fifin Okfijanti ${ }^{1}$ \\ Istiatin $^{2}$ \\ Solichul Hadi AB ${ }^{3}$ \\ Pasca Sarjana, Fakultas Ekonomi, Universitas Islam Batik \\ fifinokfiyanti@gmail.com ${ }^{1}$; Istiatinumi@gmail.com ${ }^{2}$; Shadibakri@yahoo.com ${ }^{3}$
}

Diterima: Agustus 2019, Disetujui: September 2019, Dipublikasikan: Oktober 2019

\begin{abstract}
The purpose of this study was to recognize (1) to determine the effect of motivation, professionalism and commitment to employees performances in the general part of the Sukoharjo local government. (2) To determine the effect of motivation on employee performance in the general section of the Sukoharjo Regional Government. (3) To determines the effect of professionalism on employees performances in the general section of the Sukoharjo Regional Government. (4) To determine the effect of commitment on employees performance in the general section of the Sukoharjo Regional GovernmentThe study was conducted in the General Sections of the Sukoharjo Regional Government.

The population used by employees in the General Section of the Sukoharjo Regional Government was 85 employees. The sample used was full employees. Dataaccollection techniques withs observations, documentation, questionnaires and bibliography. Proofs of hypothesis in this study use multiples linear regression analysis model.

The results of this study are motivation variables positively and significantly affect on employee performances. Professionalism variables positively and significantly affect on employee performances. Commitment avariable positively and significantly affect on employee performance. Variable of motivation, professionalism and commitment together influence in Pemda Sukoharjo. Leaders to improve the motivation, professionalism and work commitment of employee of the general section of the Sukoharjo regional government should conduct related training.
\end{abstract}

Keywords: Motivation, professionalism, commitment and performance

\begin{abstract}
Abstrak
Tujuan dari penelitian ini adalah untuk mengetahui (1) untuk mengetahui pengaruh motivasi, profesionalisme dan komitmen terhadap kinerja karyawan pada bagian umum pemerintah daerah Sukoharjo. (2) Untuk mengetahui pengaruh motivasi terhadap kinerja pegawai pada bagian umum Pemerintah Daerah Sukoharjo. (3) Untuk mengetahui pengaruh profesionalisme terhadap kinerja pegawai pada bagian umum Pemerintah Daerah Sukoharjo. (4) Untuk mengetahui pengaruh komitmen terhadap
\end{abstract}


kinerja pegawai pada bagian umum Pemerintah Daerah Sukoharjo. Penelitian dilakukan pada Bagian Umum Pemerintah Daerah Sukoharjo.

Populasi yang digunakan oleh karyawan di Bagian Umum Pemerintah Daerah Sukoharjo adalah 85 karyawan. Sampel yang digunakan adalah karyawan penuh. Teknik pengumpulan data dengan observasi, dokumentasi, kuesioner dan daftar pustaka. Bukti hipotesis dalam penelitian ini menggunakan model analisis regresi linier berganda.

Hasil penelitian ini adalah variabel motivasi berpengaruh positif dan signifikan terhadap kinerja karyawan. Variabel profesionalisme berpengaruh positif dan signifikan terhadap kinerja karyawan. Komitmen yang tersedia berpengaruh positif dan signifikan terhadap kinerja karyawan. Variabel motivasi, profesionalisme dan komitmen berpengaruh bersama di Pemda Sukoharjo. Pimpinan untuk meningkatkan motivasi, profesionalisme dan komitmen kerja pegawai bagian umum pemerintah daerah Sukoharjo harus melakukan pelatihan terkait.

Kata kunci: motivasi, profesionalisme, komitmen, kinerja

\section{PENDAHULUAN}

Seiring dengan perkembangan zaman, akan membuka wawasany ang lebih maju untuk birokrasi agar bisa berfungsididalam upaya mempercepat perubahan masyarakat agar berkembang dan semakin modern. Cara mengatasi perubahan tersebut, sebaiknya birokrasi mempunyai fungsi penting didalam melayani masyarakatbanyak, supaya birokrasi itu bisa terwujuddengan apa yang diharapkannya.

Sesuai diungkapkan Merisa et al (2017) SDM bisa disebut berkualitas apabila mereka mempunyai keahlian dan kemampuan untuk melakukan tanggung jawab yang dibebankan kepadanya. Di pemerintah, dimana fungsi pengawasan adalah fungsi dan tanggung jawab seorang kepala pemerintah, dimana Kabupaten adalah tanggungjawab Bupati. Oleh karena itu pengawasan memegang perananyang sangat penting dalam menjalankanpekerjaan sertatugas pemerintah. Pengawasan dilaksanakan dengan tujuan untuk memastikan jalannya pekerjaan apakah lancar atau tidak.

Adapun tuntutan masyarakat agar bisa menciptakan pemerintah yang lebih baik didalam melaksanakan pemerintahan pusat ataupun daerah merupakan kiprah instansi pengawasdaerah. Saat ini masyarakat bosan dengan maraknya birokrasi korupsi, yang kian meningkat ( Adri , 2017).

Guna meningkatkan harapan itu perlu langkah yang lebih realistis dan sistematis dalam memposisikan sumber daya manusia pada lembaga pengawas Kabupaten Sukoharjo. Dimulai dari atasannya sampai dengan staf yang membantuserta memberikan dukungan dalam keberhasilan pemimpin lembaga pengawasan. 
Rusjiana (2016) menyatakan penilaian kinerja merupakan hasil kerja pegawaididalam lingkup tanggungjawabnya, dapat dikatakan bahwa penilaian kinerja pegawai dapat dilihat dari seberapa besar hasil dari pencapaiann kinerja perusahaan atau instansinya.

Biasanya kinerja perusahaan dipengaruhi oleh faktor internal dan eksternal. Faktor internal biasanya memberikan pengaruh pada kinerja perusahaan. Untuk meningkatkan kinerja karyawan dibutuhkan banyak variabel yang mendukung, antara lain motivasi, profesionalisme dan komitmen kerja.

Pada saat ini layanan yang diberikan karyawan tidak sesuai yang diharapkan oleh masyarakat. Aparatur negara dan pemerintah sebagai abdi negara dan masyarakat dibutuhkan untuk menjalankan kegiatan yang dibuatpemerintah dalam melaksanakan pembangunan nasional.

Menurut penelitian mandasari, Nuswantoro (2016) motivasi berpengaruh positif dan signifikan terhadap kinerja pegawai yang berarti bahwa semakin meningkat motivasi maka kinerja pegawai akan semakin meningkat juga. Berdasarkan jawaban dari responden, semua responden memberi persepsi yang sangat baik terhadap motivasi.

Menurut penelitian Fajar Merisa, Utami (2017) profesionalisme berpengaruh positif dan signifikan terhadap kinerja pegawai. Hal ini membuktikan adanya profesionalisme yang berprinsip kepada efektif dan efisian sehingga memberikan pengaruh dalam meningkatkan kinerja karyawan. Setiap karyawan dianjurkan untuk bisa memiliki sikap profesionalisme dalam bekerja agar bisa mengoptimalkan skill, waktu, tenaga, ilmu pengetahuan dan sumber daya sehingga akan berpengaruh terhadap kinerja yang dilakukan oleh karyawan.

Selain profesioanalisme dan motivasi adapun faktor lain yang tidak dapat kita abaikan fungsinya dengan kinerjaadalah komitmenkerja. Pada saat ini komitmen organisasi mendapat perhatian dari penelitii perilaku organisasi.

Komitmen organisasi diciptakan atas kepercayaan karyawan pada nilai organisasi, keiklasan karyawan membantu menciptakan tujuan organisasi serta loyalitas untuk bertahan menjadi anggota organisasi. Jikalau pegawai merasakan jiwanya sudah terikat dengan nilai organisasional maka karyawan akan merasakankesenangan di dalam melaksanakan pekerjaan maka kinerjanya akansemakin meningkat. 
Apabila didalam suatu organisasi setiap individu sadar akan kewajiban dan haknya didalam organisasi dengan tidak melihat kedudukan dan jabatan masingmasing individu maka komitmen akan tercapai,karena tercapainya tujuan organisasi adalah hasil kerja dariseluruhanggota organisasi yang sifatnya kolektif (Respatiningsih, Sudirjo, 2015).

Komitmenyang rendah menunjukkan kurangnya tanggungjawab karyawan dalammenjalankan tugasnya. Dengan semakin tingginya komitmen pegawai terhadap organisasi maka otomatis kinerja karyawan akan meningkat juga.

Dari beberapa penelitian yang menghubungkan variabel komitmen dan motivasi organisasi dengan kinerja menunjukkan hubungan yang bervariasi dan tidak konsisten. Contohnya, Victoria Jouita et al (2016)mengatakanMotivasikerja memilikihubungan yangpositif, sedangkan (Theodora Olivia, 2015) bahwa motivasi memiliki hubungan yang negatif terhadap kinerja, penelitian diatas menjadi sesuatu yang sangat menarik untuk dilakukan penelitian .

Sesuai dengan latar belakang yang diuraikan diatas maka peneliti tertarik untuk melakukan penelitian dengan judul : “ Kinerja Karyawan Di tinjau Dari Motivasi, Profesionalisme Dan Komitmen ( Studi Kasus Pada Bagian Umum Pemda Sukoharjo).

\section{METODE PENELITIAN}

Subjek penelitian adalah pegawai bagian umum Pemda Sukoharjo. Sedangkan obyek dari penelitian ini adalah pembuktian antara pengaruh motivasi, profesionalisme, dan komitmen dengan kinerja karyawan dibagian umum Pemda Sukoharjo. Populasi dalam penelitian ini adalah pegawai bagian umum Pemda Sukoharjo yang jumlahnya 85 karyawan. Karena jumlahnya kurang dari 100 karyawan, maka seluruh populasinya dijadikan sampel dalam penelitian.

Penelitian ini dengan menggunakan data kuantitatif yaitu dengan menggunakan data yang berupa angka dari jawaban hasil responden. Dalam penelitian ini pengumpulan data yang digunakan adalah dengan cara menyebar angket pada semua responden. Sedangkan teknik analisis data yang dipakai yaitu analisis deskriptif kuantitatif, melalui analisis regresi linear berganda, uji asumsi klasik, uji simultan atau uji F dan uji parsial atau uji $\mathrm{T}$. 
Penelitian ini terdiri dari 3 (tiga) variabel bebas, dan 1 (satu) variabel terikat. Variabel bebas atau independen terdiri dari motivasi, variabel profesionalisme, variabel komitmen. Variabel dependen (terikat) adalah kinerja.

\section{HASIL PENELITIAN}

Berdasarkan jenis kelamin bagian umum Pemda Sukoharjo terdiri dari laki-laki 59 orang $(69,4 \%)$, perempuan 26 orang $(30,6 \%)$.

Berdasarkan usia terdiri dari: 21-30 tahun 36 orang (42,4\%), 31-40 tahun 30 orang $(35,3 \%), 41-50$ tahun 12 orang $(14,1 \%)$, >51 tahun 7 orang $(8,3 \%)$.

Berdasarkan masa kerja : <5 tahun 10 orang (11,8\%), 5-10 tahun 40 orang (47,1\%), 10-20 tahun 31orang (36,5\%) dan >20 tahun 4 orang $(4,7 \%)$.

\section{Uji Asumsi Klasik}

Menunjukkann bahwa nilai kolmogorov-smirnov adalah 0,060 dan signifikan pada 0,200 dimana nilai signifikannya $>0.05$ hal ini berarti ada residual terdistribusi secara normal. Serta semua data berdistribusi normal dan sebaran data ada disekitar garis diagonal maka dapat dikatakan bahwa model regresi memenuhi asumsi normalitas.

a. Uji Multikolinearitas

Modelregresi yang baik adalah yang tidakterjadi korelasi diantara variabel independen. Ringkasan Hasil Pengujian Multikolinearitas Dengan Menggunakan VIF. Penelitian ini menunjukkan bahwa masing-masing variabel nilai VIF dalam model regresi tidak terkena adanya gejala multikolinearitas dikarenakan nilai VIF yang < dari 10 .

b. Uji Heteroskedastisitas

Scatterplot yang dihasilkan dari output program SPSS adalah :

Hasil pengujian menunjukkan bahwa titik-titik tersebar secara acak dan tidak berbentuk pola yang jelas, menyebar baik diatas ataupun dibawah angka 0 pada sumbu Y. Ini artinya tidak terjadi penyimpangan asumsi klasik heteroskedastisitas pada model regresi yang dibuat. 


\section{Analisis Regresi Linear Berganda}

\section{Persamaan Regresi}

Berdasarkan analisis Regresi Berganda dengan program SPSS diperoleh hasil sebagai berikut :

1. Besarnya konstanta yaitu 5,197 hal ini berarti apabila $\mathrm{X} 1, \mathrm{X} 2, \mathrm{X} 3$ dan konstan atau $\mathrm{X}=0$ berati kinerja sebesar 5,197.

2. X1 (motivasi) menunjukkannilai koefisien 0,345 hal ini berarti apabila ada peningkatan motivasi sebesar $1 \%$ terhadap instansi sehinggakinerja juga mengalami peningkatansebesar variabel pengalinya yaitu 0,345. Dengan asumsi variabel independen yang lainnya dianggap konstan.

3. X2 (profesionalisme) menunjukkan nilai koefisien sebesar 0,257 ini berarti apabilaterjadi peningkatan penyebab motivasi sebesar 1\% terhadap instansi berarti kinerja juga akan meningkatan sebesar variabel pengalinya yaitu 0.257. Dengan asumsi variabel independen yang lain dianggap konstan.

4. X3 (komitmen) menunjukkan nilai koefisien sebesar 0.223 ini berarti jika ada peningkatan penyebab motivasi $1 \%$ terhadap instansiberarti kinerja pasti juga mengalami peningkatan sebesar variabel pengalinya yaitu 0,223. Dengan asumsi variabel independen yang lain dianggap konstan.

\section{Koefisien Korelasi (R)}

Nilai R untukvariabel motivasi, profesionalisme dan komitmen adalah sebagai berikut : besarnya koefisien korelasi sebesar 0,751 ini adanya hubungan yang positifdiantara variabel motivasi, profesionalisme dan komitmen yang berkesinambungan terhadap variabel kinerjadimana dapat dikategorikans kuat. Menurut teori Sugiono inteval koefisien antara 0,60 - 0,799 tingkat hubungannya dikategorikan Kuat.

Sedangkan $\mathrm{R}^{2}$ sebesar 0,654 ini artinya 65,45 variabel kinerja bisa dijelaskan dari ke 3 variabel motivasi, profesionalisme dan komitmen sedangkan sisanya $34,6 \%$ dijelaskan akibat yang lain diluar model. 


\section{Uji hipotesis}

\section{Uji simultan (uji F)}

Dari uji $\mathrm{F}$ atau ANOVA diatas didapat nilai $\mathrm{F}$ hitung sebesar 34,946. Hal ini menunjukkan bahwa F hitung yaitu 34,946 > F tabel yaitu 3,96 dengan probabilitas sebesar 0,000. Karena nilai probabilitasnya lebih kecil dari 0,05 maka dapat dikatakan bahwa variabel motivasi, profesionalisme dan komitmen secara bersama-sama berpengaruh positif dan signifikan terhadap kinerja karyawan di Bagian umum Pemda Sukoharjo.

\section{Uji t ( Parsial )}

Didalam penelitian ini bahwa t tabel sebesar 1,66320. Hasil uji parsial dari masing-masing variabel sebagai berikut :

Berdasarhasil pengujian diatas bahwa variabel bebas dapat dijelaskan sebagai berikut :

1. Variabel motivasi menunjukkan $\mathrm{t}$ hitung > dari pada $\mathrm{T}$ tabel yaitu 3,264 > 1,66320, berarti variabel motivasi berpengaruh positif dan signifikan terhadap kinerja karyawan bagian umum Pemda Sukoharjo. Dengan demikian hipotesa ke dua diterima.

2. Variabel profesionalisme menunjukkan $\mathrm{t}$ hitung lebih besar dari pada t tabel yaitu 2,063>1,66320, berarti variabel profesionalisme berpengaruh positif dan signifikan terhadap kinerja karyawan bagian umum Pemda Sukoharjo. Dengan demikian hipotesa ke tiga diterima.

3. Variabel komitmen menunjukkan t hitung lebih besar dari pada t tabel yaitu $2,164>1,66320$, berarti variabel komitmen berpengaruh positif dan signifikan terhadap kinerja karyawan bagian umum Pemda Sukoharjo. Dengan demikian hipotesa ke empat diterima.

\section{Pembahasan}

Berdasarkan hasil pengujian dapat di lihat secara simultanvariabel independen yaitu motivasi, profesionalismedan komitmen bersama-sama berpengaruh positif dan signifikan terhadap kinerja karyawan. Sedangkan secara parsial motivasi, 
profesionalisme dan komitmen berpengaruh positif dan signifikanterhadap kinerja karyawan di bagian umum Pemda Sukoharjo.

\section{Pengaruh motivasi, profesionalisme dan komitmen secara bersama-sama terhadap kinerja karyawan.}

Motivasi, profesionalisme dan komitmensecara bersama-sama berpengaruh positif dan sifnifikan terhadap kinerja karyawan di Bagian umum Pemda Sukoharjo. F hitung sebesar 34,946 > dari F tabel yaitu 3,96 dengan probabilitas 0.000. Karena nilai probabilitas jauh < dari 0.05 maka model regresi ini bisa dipakai untuk memprediksi kinerja pada bagian umum Pemda Sukoharjo.

Ini menunjukkan bahwa semakin baik motivasi, profesionalismedan komitmen yang dimiliki oleh pegawai berarti kinerjakaryawan akan semakin baik, begitu juga sebaliknya. Dalam hal ini sesuai dengan penelitian yang sudah saya lakukan bahwa motivasi, profesionalismedan komitmen secara bersama-sama berpengaruhpositif dan signifikan terhadap kinerja karyawan di Bagian umum Pemda Sukoharjo. Hal ini sejalan pula dengan penelitian yang telah dilakukan oleh Fajar Merisa, Utami Wiji, Sunardi, Sudarsih (2017) menyebutkan bahwa KualitasSDM, profesionalismekerja,dankomitmensecara simultan berpengaruhpositif dansignifikanterhadap kinerja pegawaiPDAM Jember. Sehingga bisa disimpulkan bahwa kinerja dan keberhasilan seseorang didalam melakukan pekerjaan ditentukan oleh motivasi, prosefionalisme dan komitmen terhadap bidangyang ditekuni.

\section{Pengaruh motivasi kerja terhadap kinerja karyawan}

Hipotesis kedua menunjukkan bahwa motivasi terpengaruh positif dan signifikan terhadap kinerja karyawan pada Bagian Umum Pemda Sukoharjo. Hal ini ditunjukkan nilai t hitung lebih besar dari t tabel yaitu 3,264 > 1,66320.

Ini menunjukkan bahwa semakin baik motivasi kerja yang ada pada pegawai maka kinerja pegawai akan meningkat.Menurut penelitian terdahulu yang telah dilakukan oleh Mandasari,Nurwanto (2016) bahwa motivasi berpengaruh positif dan signifikan terhadap kinerja karyawan. Hal ini sesuai dengan penelitian yang saya 
lakukan bahwa motivasi kerja berpengaruh positif dan signifikan terhadap kinerja pada bagian umum Pemda Sukoharjo.

\section{Pengaruh profesionalisme kerja terhadap kinerja karyawan}

Hipotesis ketiga yaitu bahwa profesionalisme terpengaruh positif dan signifikan terhadap kinerja pegawai pada Bagian Umum Pemda Sukoharjo. Seperti ditunjukkann nilai t hitung > t tabel yaitu 2,063 > 1,66320.

Ini menunjukkan bahwa semakin baik profesioanlisme kerja yang ada dalam diri karyawan maka kinerja karyawan akan meningkat juga. Menurut penelitian terdahulu yang telah dilakukan oleh Taufik Akbar ( 2015 ) bahwa profesionalisme kerjaberpengaruhterhadapprestasikerjapegawai Pegawai Di BadanPerpustakaan Provinsi Sulawesi Utara. Hal ini sejalan dengan penelitian yang saya lakukan bahwa profesionalisme berpengaruh positif dan signifikan terhadap kinerja pegawai di bagian umum Pemda Sukoharjo.

\section{Pengaruh komitmen kerja terhadap kinerja karyawan}

Berdasarka hasil SPSS, hasil penelitian pada persamaan ke empat menjelaskan bahwa komitmen kerja berpengaruh positif dan signifikan terhadap kinerja karyawan di bagian umum Pemda Sukoharjo. Hipotesis keempat menyebutkan bahwa komitmen terpengaruh positif dan signifikan terhadap kinerja karyawan pada Bagian Umum Pemda Sukoharjo. Hal tersebut ditunjukkan bahwa t hitung> dari t tabel yaitu 2,164 > 1,66320 .

Dapat disimpulkan bahwa semakin baik komitmen kerja yang ada pada karyawan mengakibatkan kinerja karyawan akan semakin baik. Berdasarkan penelitian terdahulu yang telah dilakukan oleh Fajar Merisa, Utami Wiji, Sunardi, Sudarsih (2017) menyebutkan bahwakomitmenberpengaruhpositif dansignifikanterhadapkinerja karyawanPDAM Jember. Dalam hal ini sesuai dengan penelitian yang sudah saya lakukan bahwa komitmen berpengaruh secara positif dan signifikan terhadap kinerja pada Bagian Umum Pemda Sukoharjo. 


\section{Kesimpulan}

Tujuan daripada penelitian ini adalah untuk mengetahui pengaruh motivasi, profesionalisme dan komitmen kerja di Bagian umum Pemda Sukoharjo. Dari hasil penelitian serta pembahasan diatas dapat diambil kesimpulan sebagai berikut :

1. Berdasar hasil uji simultan ( uji F) menunjukkan bahwa motivasi, profesionalisme dan komitmen bersama-sama berpengaruh positif dan signifikan terhadap kinerja karyawan di Bagian umum Pemda Sukoharjo. Dalam hal ini berarti semakin baik motivasi, profesionalisme dan komitmen yang dimiliki pegawai maka kinerja karyawan akan semakinbaik pula. Demikian juga sebaliknya.

2. Berdasarkan hasil ujit (uji parsial) menunjukkan :

a. Motivasi berpengaruh positif dan signifikan terhadap kinerja karyawan di Bagian umum Pemda Sukoharjo. Dalam hal ini semakin baik motivasi kerja yang ada dalam diri karyawan maka kinerja pegawai akan semakinbaik juga.

b. Profesionalisme berpengaruh positif dan signifikan terhadap kinerja karyawan di Bagian umum Pemda Sukoharjo. Dalam hal ini maka semakin baik profesionalisme kerja yang ada dalam karyawan maka kinerja karyawan semakin baik juga

c. Komitmen berpengaruh positif dan signifikan terhadap kinerja karyawan di bagian umumPemda Sukoharjo. Hal ini berarti semakin baik komitmen kerja maka kinerjapegawai akan semakin baik pula, Begitu juga sebaliknya.

3. Hasil Regresi menunjukkan bahwa adanya hubungan yang positif antara motivasi, profesionalisme serta komitmen yang berkesinambungan dengan variabel kinerja yang dapat dikategorikan kuat.

4. Hasil uji $\mathrm{R}^{2}$ menunjukkan bahwa $65,4 \%$ ini berarti variabel kinerja bisa dijelaskan dari ke 3 variabel motivasi, profesionalisme, dan komitmen sedang 34,6\% dijelaskann oleh sebab yang lain diluar model.

\section{Implementasi}

1. Memberi pujian bagi karyawan yang mempunyai kinerja yang baik, agar karyawan semakin termotivasi.

2. Pelatihan-pelatihan dilakukan dengan mengirim pegawai untuk dapat meningkatkan profesional. 


\section{Saran}

Berdasarkan hasil penelitian tentang Kinerja karyawan di tinjau dari motivasi, profesionalisme dan komitmen ( studi kasus pada Bagian umum Pemda Sukoharjo, maka peneliti memberikan saran sebagai berikut :

1. Bagian Umum Pemda Sukoharjo harus menentukan ukuran yang pasti pada permulaan tahun. Karena keahlian dan kemampuan akan menentukan kinerja karyawan di Bagian Umum Pemda Sukoharjo baik untuk PNS maupun tenaga harian lepas.

2. Dalam meningkatkan motivasi, profesionalisme dan komitmen kerja karyawan Bagian Umum Pemda Sukoharjo sebaiknya melakukan pelatihan yang berhubungan dengan upaya untuk menambah profesionalisme.

3. Pimpinan Bagian Umum Pemda Sukoharjo tidak membeda-bedakan dalam memberikan penilaian pada begawai baik tenaga harian lepas (THL) maupun pegawai negri sipil.

4. Diharapkan motivasi, profesionalisme dan komitmen secara simultan berpengaruh positif dan signifikan, oleh karena itu di Bagian Umum Pemda Sukoharjo sebaiknya lebih memperhatikan pelaksanaan seleksi dan rekruitmen khususnya terhadap tenaga harian lepas.

\section{DAFTAR PUSTAKA}

A.M, Sardiman. 2006. Interaksi dan Motivasi Belajar dan Mengajar. Jakarta : PT Raja Grafindo Persada.

Dwiyanto (2011:157)Mengembalikan kepercayaan Publik Melalui Reformasi Birokrasi. Penerbit Gramedia Pustaka Utama.

Fajar Merisa, Utami (2017)KualitasSumber Daya Manusia,ProfesionalismeKerja, Dan KomitmenSebagaiFaktor Pendukung Peningkatan KinerjaKaryawan PDAM KabupatenJember. Vol. 4 No. 1 (131-135)

Katiandagho Christian, Mandey SilvyaL, Mananeke Lisbeth (2014) PengaruhDisiplinKerjaKepemimpinanDanMotivasiTerhadapKinerja PegawaiPadaPt.Pln(Persero)Wilayah SuluttenggoAreaManado. Vol. 2, No. 3 September 2014

Mangkunegara (2013) ManajemennSDM Perusahaan. Edisi KeduaBandung : Penerbit Alfabeta, 2013. 
Melisa et al (2017) Kualitass SDM, ProfesionalismeKerja,DanKomitmenSebagai Faktor Pendukung Peningkatan Kinerja Karyawan PDAM Kabupaten Jember. 2017, volume IV (1), 131-135

Mandasari, Nuswantoro (2016) Upaya Peningkatan Kinerja Karyawan Operasional Melalui Motivasi Kerja, Disiplin Kerja Dan Lingkungan Kerja.

Pilatus Deikme. Motivasi Kerja Dan Budaya Organisasi Pengaruhnya Terhadap Kinerja Pegawai Bag. Keuangan Sekda Kab. Mimika Propinsii Papua. Vol. 1 No. 3, hhal 1980-986.

Rusjiana (2016) Pengaruh Sistem Informasi Sumber Daya Manusia Terhadap Kinerja Karyawan di PT. Rabbani Bandung. ,Vol. 510,No.1,Junik2016,521-29

Respatiningsih, Sudirjo (2015 ) Pengaruh Komitmen Organisasi, Motivasi, Kapabilitas Dan Kepuasan Kerja Terhadap Kinerja Pegawai, Vol. 4 No. 3, 2015.

Siagian (2009: 163) Kiat Meningkatkan Produktivitas Kerja, Penerbit Rineka Cipta

Sugiono . Metode Penelitian Bisnis (Pendekatan kuantitatif, Kualitatif dan R\&D). Bandung : Penerbit Alfabeta, 2012.

Sugiono. Metode Penelitian Kuantitatif, Kualitatif dan Kombinasi . Bandung : Penerbit Alfabeta 2014

Sutrisno, Edy. Managemen Sumber Daya Manusia. Jakarta : Penerbit Kencana, 2009.

https://jurnal.unej.ac.id/index.php/eJEBAUJ/article/download/4753/3499/, 5 Juli 2018

http://eprints.dinus.ac.id/17230/1/jurnal_16092.pdf, 5 Juli 2018

https://ejournall.unsrat.ac.id/index.php/emba/article/view/11663, 5 Juli 2018

http://jurnal.untagsmg.ac.id/index.php/sa/article/view/162, 5 Juli 2018

http://repositori.uinalaudin.ac.id/8186/1/Abdullahadri.pdf,5 juli 2018 